\title{
Effect of Normosil Probiotic Supplementation on the Growth Performance and Blood Parameters of Broiler Chickens
}

\author{
Airat Khabirov' ${ }^{1}$, Fail Khaziakhmetov ${ }^{1}$, Vyacheslav Kuznetsov' ${ }^{2}$, Hamit Tagirov ${ }^{1}$, Maksim Rebezov ${ }^{3,4}$, \\ Aleksandra Andreyeva ${ }^{1}$, Almaz Basharov', Zhanibek Yessimbekov ${ }^{5}$, Muhammad Ayaz ${ }^{6, *}$ \\ ${ }^{1}$ Department of Physiology, Biochemistry and Animal Feeding, Bashkir State Agrarian University, Ufa, RUSSIA. \\ ${ }^{2}$ Scientific-innovative enterprise "Bash-Incom", Ufa, RUSSIA. \\ ${ }^{3}$ Center of Biophotonics of A. M. Prokhorov General Physics Institute, Russian Academy of Science, Moscow, RUSSIA. \\ ${ }^{4}$ Department of Biotechnology and Food Products of Ural State Agrarian University, Yekaterinburg, RUSSIA. \\ ${ }^{5}$ Food Engineering Department, Shakarim University of Semey, Semey, KAZAKHSTAN. \\ ${ }^{6}$ Department of Pharmacy, University of Malakand, Khyber Pakhtunkhwa,18000, PAKISTAN.
}

\begin{abstract}
Purpose: This study was aimed to investigate the effects of probiotic "Normosil" containing a mixture of living cultures of Lactobacillus and Enterococcus strains at a concentration of $1 \times 10^{6}$ and $1 \times 10^{7} \mathrm{CFU} / \mathrm{mL}$ was assessed. Materials and Methods: Effect of Normosil on the growth performance, hematological and biochemical factors of Arbor Acres broilers from a day-old to 42 -day old $(n=175,1$ control +4 experimental groups) daily and periodically. Results: Results showed that Normosil $\left(1 \times 10^{6} \mathrm{CFU} / \mathrm{mL}\right)$ had a relatively better growth performance and showed an increase in the average daily growth by $10.6 \%-13.0 \%$ compared to control. In comparison to control, broilers provided with daily and periodic dose of Normosil showed an increase in the level of blood erythrocytes by $5.6 \%$ and $14.1 \%$ after 21 days, respectively; and an increase in hemoglobin, glucose, total protein, albumin, sodium, potassium and calcium by $4.9 \%$ and $10.9 \%, 12.3 \%$ and $17.4 \%, 0.5 \%$ and $5.7 \%, 3.7 \%$ and $14.4 \%, 2.1 \%$ and $5.0,17.0 \%$ and $33.3 \%$ and $7.7 \%$ and $21.2 \%(p<0.05)$, respectively after 42 days of growth. Nutrient digestibility in context to organic matter, raw protein, raw fat and nitrogen-free extractive compounds in broilers fed with periodic and daily doses of Normosil $\left(10^{6} \mathrm{CFU} / \mathrm{mL}\right)$ was higher than in control by $4.4 \%-6.6 \%, 2.5 \%-6.2,1.6 \%-5.5 \%$ and $8.2 \%-12.2 \%$, respectively. Compared to control, the femoral muscles had a higher protein content of $6.0 \%$ and $15.7 \%$ (experimental groups III and IV); low carcass fatness by $8.1 \%$ (group IV); and low content of connective tissue. Conclusion: This study suggests the potential benefits of Normosil supplementation for improving the growth and quality of broilers.
\end{abstract}

Key words: Probiotics, Biochemical parameters, ArborAcres cross broilers, Normosil, Hematological parameters, Albumin-globulin coefficient, Nutrient digestibility.

\section{INTRODUCTION}

Poultry farming is one of the most intensive and dynamic sectors of the country's agroindustrial complex. It is considered as the major supplier of protein rich diet for the population. The worldwide trend in the production of poultry products is the choice of safe production technologies, which mainly involves the rejection of the use of antibiotics in growing farm animals and poultry. ${ }^{1}$ However, this approach is currently not adopted by all agricultural producers in the world. Since 2006, there has been a total ban on the use of feed antibiotics in EU countries. However, today, the largest consumer of antibiotics in the animal husbandry is the United States, which uses antibiotics during feeding of $80 \%$ poultry, $75 \%$ pigs and dairy cattle. A similar approach is exhibited by the livestock producers of Africa and South America. ${ }^{2}$
Submission Date: 15-04-2020; Revision Date: 17-07-2020; Accepted Date: 23-10-2020

DOI: 10.5530/ijper.54.4.199 Correspondence: Dr. Muhammad Ayaz Department of Pharmacy, University of Malakand, Khyber Pakhtunkhwa-18800, PAKISTAN.

Phone: $+92-346-8004990$

E-mail: ayazuop@gmail.com

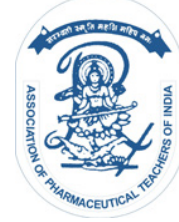

www.ijper.org 
Antibiotics are used not only for preventive and therapeutic purposes but also to stimulate rapid growth and control disease in the organism. Particularly relevant is their use in the first days of life in order to prevent diseases. ${ }^{3}$ Such indiscriminate use of antibiotics usually produces antibiotic resistance and residues in animal products. Of particular concern is the use of those drugs that are used to treat human diseases. Because animals harbor micro-organisms that can acquire resistance to these drugs, there is a high possibility that a person eating such meat will acquire the resistantbacteria to those antibiotics, along with small amounts of drugs, thereby reducing their resistance to infections and beneficial micro flora. ${ }^{4}$

Russian animal products producers are increasingly focused on identifying alternative solutions, of which, the use of probiotic preparations based on living forms of bacteria with pronounced antagonism to pathogenic and conditionally pathogenic micro-organisms in the animals are one of the major strategies. ${ }^{5}$ The use of probiotics from the initial days of life allows normalizing the composition of the intestinal micro flora and protecting against pathogenic microbes, thereby rendering a positive effect on the intestinal microbial balance. Bacteria that are a part of probiotics contribute to a better digestibility of the feed and subsequent absorption by animals. ${ }^{4,6}$ However, lack of regulation during the use of probiotics often leads to a decrease in their effectiveness, suppression of own micro flora and the increased frequencies of infections in the immuneweakened organisms. ${ }^{7}$

The range of such probiotics commercially available is constantly expanding; new probiotic supplements are entering the market, requiring an assessment of the effectiveness of their use. These include the new probiotic supplement "Normosil", developed by "BashInkom" Company, Ufa city, Russia. Normosil is an alternative to feed antibiotics. The unique ratio of micro-organisms and their complex action provides a quick and effective healing effect to the animals and birds; it does not take time to activate the beneficial micro-organisms because they are in an active state and begin functioning immediately upon ingestion. It renders comprehensive protection against various types of pathogenic and conditionally pathogenic micro-organisms. ${ }^{8}$ Normosil is safe for human, animals, birds and is environment-friendly. Normosil includes a mixture of living cultures, including strains of lactic acid bacteria: Lactobacillus brevis B-3 (Russian National Collection of Industrial Micro-rganisms B 6338), L. plantarum 8RAZ (B 11007), L. acidophilus 457 (B 2213), Enterococcus faecium UDS 86 (Russian National Collection of Industrial Micro- organisms B-4054) and enter sorbent. Normosil bacterial component resist the high $\mathrm{pH}$ and other harsh conditions in the host's body (acid and bile resistance), which further warrants its effectiveness in the gastrointestinal tract. ${ }^{9}$ The objective of this study was to assess the effect of "Normosil" probiotic on the live weight gain, hematological and biochemical parameters, digestibility of feed nutrients, slaughter qualities, chemical composition of femoral muscles and economic efficiency of broiler chickens.

\section{MATERIALS AND METHODS}

\section{Study site and experimental design}

The current study was completed at "Sterlibashevskaya Poultry Farm" LLC (Republic of Bashkortostan, Russia). Random sampling was performed and five groups ( 1 control +4 tests) of daily age broiler chickens of Arbor Acres were made; each group comprising 35 chickens. Poultry was reared for 42 days using the feeding program that complied with the requirements for the growing technology of Arbor Acres broiler chickens. For feeding of 10-day broiler chickens, the starter broiler feed was used in the form of mini-pellets. From 11 to 24-day-old, feeding was carried out using the main broiler feed in the form of pellets of diameter 2-3.5 mm. For 25-day broiler chickens, the feed with the granules of $3.5 \mathrm{~mm}$ was used in the diet until slaughtering process. Temperature, air condition and ventilation in the floor pens were automatically controlled. Lactic acid bacteria based "Normosil" probiotic preparation was given along with drinking water to the broiler chickens

Table 1: Types of broiler groups and their feeding patterns and timeline of probiotic supplementation, $n=35 /$ group.

\begin{tabular}{|c|c|c|}
\hline Group & Feeding features & $\begin{array}{c}\text { Period of } \\
\text { giving the } \\
\text { preparation }\end{array}$ \\
\hline Control & Basic diet & $1-42$ \\
\hline Experimental I & $\begin{array}{c}\text { Basic diet }+ \\
\text { "Normosil" at a dose of } \\
1 \times 10^{7} \mathrm{CFU} / \mathrm{mL}\end{array}$ & $1-42$ \\
\hline Experimental II & $\begin{array}{c}\text { Basic diet }+ \\
\text { "Normosil" at a dose of } \\
1 \times 10^{7} \mathrm{CFU} / \mathrm{mL}\end{array}$ & $\begin{array}{c}1-10,15-24, \\
29-38\end{array}$ \\
\hline Experimental III & $\begin{array}{c}\text { Basic diet }+ \\
\text { "Normosil" at a dose of } \\
1 \times 10^{6} \mathrm{CFU} / \mathrm{mL}\end{array}$ & $1-42$ \\
\hline Experimental IV & $\begin{array}{c}\text { Basic diet }+ \\
\text { "Normosil" at a dose of } \\
1 \times 10^{6} \mathrm{CFU} / \mathrm{mL}\end{array}$ & $1-10,15-24$, \\
& \multicolumn{2}{|c|}{$29-38$} \\
\hline
\end{tabular}


at the rate of $1 \mathrm{~mL} / \mathrm{kg}$ of live weight of the bird (Table 1).

\section{Hematological and biochemical parameter analyses}

Collection of whole blood and serum isolation were performed at the veterinary center of The Federal State Educational Institution of Higher Education "Bashkir SAU", State Budgetary Institution "Bashkir Research and Production Veterinary Laboratory". Blood sampling from broiler chickens was carried out from the wing vein above the elbow joint at 21 and 42 days of age. Hematological and blood related biochemical analysis were performed at 21 and 42 days of age. Hemoglobin $\mathrm{Hb}$ contents quantification was performed employing cyan hemoglobin method. ${ }^{10}$ Whereas, Total cholesterol content (TCC) was measured via enzymatic colorimetric method. Further, contents of proteins, albumin and lipids were assessed using respective diagnostic kits. All the blood biochemical parameters were determined using "Vital Diagnostic" reagents on a Stat Fax 3300 semi-automatic biochemical analyzer ("Awareness Technology", USA).

\section{Growth performance analysis}

Assessments of body weight, daily increase in weight, every day feed utilization, death rate, nutrient digestibility and muscle mass were determined for all the groups. All the experimental broiler chickens were weighed weekly before morning feeding till 42 days of age. Daily weight gains were then measured for the sampling periods. Chemical composition of the muscle tissue was assessed using meat analyzer. Mortality rate was determined weekly as accumulative average; all dead birds were removed daily (morning) and weighed.

\section{Statistical Analysis}

All data were averaged and analyzed using one-way ANOVA of SPSS version 13.0 software (SPSS Inc., Chicago, IL). A $P<0.05$ was considered statistically significant.

\section{RESULTS AND DISCUSSION \\ Growth parameter analyses}

After three weeks of poultry breeding, the live weight in all the experimental groups significantly exceeded to that of the control group, specifically by $13.8 \%(p<0.05)$, $17.6 \%(p<0.01)$ and $18.7 \%(p<0.01)$ for the experimental groups III, I and II and IV, respectively (Table 2). This trend continued for following five weeks of growth in the experimental group II, wherein the weight of the broiler chickens was $12.8 \%(p<0.05)$ higher than that of the control group. The same trend was observed in the experimental group IV, wherein the broiler weight exceeded the control by $13.2 \%(p<0.05)$. After six weeks of breeding, chickens of the experimental groups I, II, III and IV increased in weight in comparison to control group by $8.2 \%, 11.1 \%, 12 \%$ and $12.9 \% \quad(p<0.05)$, respectively. The average daily live weight gain after 42 days of growing was $60.8 \mathrm{~g} /$ day, $65.8 \mathrm{~g} /$ day, $67.7 \mathrm{~g} /$ day, $67.2 \mathrm{~g} /$ day and $68.7 \%$ in the control, experimental groups I, II, III and IV, respectively. The safety index of the birds during the growing period was $94.3 \%$ in the control and experimental group IV, 97.1\% in experimental groups I and III and 100\% in experimental group II. Our results showed that the administration of probiotic Normosil via drinking water had several beneficial effects on the growth and development of Arbos Acres broilers. The improvement in the live weight of broiler chickens of the experimental group

\begin{tabular}{|c|c|c|c|c|c|}
\hline \multirow{3}{*}{ Age, week } & \multicolumn{5}{|c|}{ Group } \\
\hline & \multirow{2}{*}{ Control } & \multicolumn{4}{|c|}{ Experimental } \\
\hline & & I & II & III & IV \\
\hline 1 week & $97 \pm 2.27$ & $103 \pm 2.27$ & $108 \pm 3.16^{* *}$ & $98 \pm 2.94$ & $107 \pm 4.54$ \\
\hline 2 week & $182 \pm 5.67$ & $193 \pm 6.01$ & $195 \pm 6.04$ & $185 \pm 7.49$ & $205 \pm 7.79^{*}$ \\
\hline 3 week & $470 \pm 18.5$ & $553 \pm 22.9^{* *}$ & $558 \pm 21.1^{* *}$ & $535 \pm 26.52^{*}$ & $558 \pm 27.33^{\star *}$ \\
\hline 4 week & $1163 \pm 53.47$ & $1214 \pm 57.60$ & $1272 \pm 58.36$ & $1221 \pm 53.00$ & $1282 \pm 77.05$ \\
\hline 5 week & $1778 \pm 65.56$ & $1930 \pm 66.6$ & $2006 \pm 91.9^{*}$ & $1991 \pm 92.71$ & $2012 \pm 92.1^{*}$ \\
\hline 6 week & $2594 \pm 112.9$ & $2806 \pm 101.9$ & $2883 \pm 95.8$ & $2861 \pm 115.6$ & $2928 \pm 122.1^{*}$ \\
\hline Average daily gain, $g$ & 60.8 & 65.8 & 67.7 & 67.2 & 68.7 \\
\hline
\end{tabular}

Note: ${ }^{*} p<0,05 ; * * p<0,01$ 


\begin{tabular}{|c|c|c|c|c|c|}
\hline \multirow{2}{*}{ Indicator } & \multicolumn{5}{|c|}{ Group } \\
\hline & Control & Experimental I & Experimental II & Experimental III & Experimental IV \\
\hline \multicolumn{6}{|c|}{21 days } \\
\hline Erythrocytes, $10^{12} / \mathrm{mL}$ & $2.14 \pm 0.47$ & $2.24 \pm 0.64$ & $2.26 \pm 0.67$ & $2.33 \pm 0.42$ & $2.44 \pm 0.57$ \\
\hline Hemoglobin, g/mL & $101.2 \pm 12.4$ & $108.4 \pm 8.9$ & $107.8 \pm 10.5$ & $111.6 \pm 12.6^{*}$ & $105.8 \pm 13.2$ \\
\hline Leukocytes, $10^{9} / \mathrm{mL}$ & $29.7 \pm 2.34$ & $34.6 \pm 2.51^{*}$ & $31.2 \pm 1.37$ & $32.5 \pm 2.41$ & $31.58 \pm 2.19$ \\
\hline \multicolumn{6}{|c|}{ 42days } \\
\hline Erythrocytes, $10^{12} / \mathrm{mL}$ & $2.31 \pm 0.42$ & $2.22 \pm 0.36$ & $2.24 \pm 0.63$ & $2.28 \pm 0.37$ & $2.36 \pm 0.58$ \\
\hline Hemoglobin, g/mL & $103.3 \pm 9.6$ & $106.9 \pm 7.2$ & $104.5 \pm 11.03$ & $108.3 \pm 9.7^{* *}$ & $114.5 \pm 10.6^{*}$ \\
\hline Leukocytes, $10 \% / \mathrm{mL}$ & $27.3 \pm 1.63$ & $28.9 \pm 1.21$ & $26.4 \pm 1.72$ & $27.6 \pm 2.34$ & $29.2 \pm 3.14$ \\
\hline
\end{tabular}

Note: ${ }^{*} p<0,05 ; * * p<0,01$

in comparison to control group could be attributable to better feed conversion due to probiotics. On the whole, the favorable outcomes of probiotic treatment on the growth performance are in line with previously published research studies using probiotics in broilers. ${ }^{11}$

\section{Hematological parameter analysis}

Hematological parameter analyses indicated that the probiotic Normosil harbored micro-organisms that had definite influence on the morphological picture of the blood of broiler chickens in the course of their vital activity (Table 3). The probiotic feed additive "Normosil" at a concentration of $1 \times 10^{6} \mathrm{CFU} / \mathrm{mL}$ had a more pronounced erythropoietic effect in the experimental groups in comparison to control group regardless of the frequency of administration. This was confirmed by the higher number of erythrocytes in the blood at 21 days of age by $8.9 \%$ and $14.1 \%$, respectively, in the experimental groups III and IV in comparison to control group. Furthermore, the number of erythrocytes in the experimental group I and experimental group II were $4.7 \%$ and $5.6 \%$ higher compared to control at this age, respectively. The concentration of hemoglobin was also high in all the experimental groups when compared with the control group; experimental group III exhibiting highest hemoglobin content by $10.3 \%$ compared to control at $1 \times 10^{6} \mathrm{CFU} / \mathrm{mL}$ of Normosil. The daily and periodic intake of Normosil probiotic at a concentration of $1 \times 10^{7} \mathrm{CFU} / \mathrm{mL}$ showed an increase in the hemoglobin concentration by only $7.2 \%$ and $6.6 \%$, respectively. The quantitative composition of leukocytes in all the groups was within the physiological limits. However, the tendency of increased number of leukocytes was typical for all the experimental groups. Interestingly, enhanced leukopoietic effect was observed when "Normosil" was given daily to the experimental group I $\left(10^{7} \mathrm{CFU} / \mathrm{mL}\right)$ and experimental group III $\left(10^{6} \mathrm{CFU} / \mathrm{mL}\right)$ by $16.5 \%$ and $9.5 \%$, respectively (Table 3). In this case, it is necessary to distinguish the nature of the increase in the number of leukocytes that can be due to reactive leukocytosis and pathological leukocytosis, which occurs, inter alia, in the process of inflammatory diseases caused by micro-organisms. The absence of significant differences and consistency with our results in the analysis of biochemical parameters in comparison to other studies suggests that there are no pathological conditions in the broilers. ${ }^{12}$ In comparison to the hematological analysis at 21 days of age, the results at 42 days of age were characterized by decreased values of all the studied parameters, which in turn reflects the normal growth characteristics of birds that are characterized by the highest growth rate during the period of 20-30 days. At 42 days of age, the administration of "Normosil" at $10^{7} \mathrm{CFU} / \mathrm{mL}$ showed an increase in the hemoglobin concentration by $4.9 \%$ and $10.9 \%$ for daily and periodic administration, respectively, in the broilers. Similar values were observed upon providing "Normosil" at a concentration of $10^{6} \mathrm{CFU} / \mathrm{mL}$ to the broilers $(3.5 \%$ and $1.2 \%$ for daily and periodic administration). A small increase (2.2\%) in the number of erythrocytes was found only in the blood of broiler chickens of the experimental group IV upon "Normosil" administration. A relatively greater leukopoietic effect was characteristic for the experimental group I and IV by $5.9 \%$ and $7.0 \%$, respectively.

In context to the mechanism of influence of probiotic preparations on the blood system, the most probable action of probiotic micro-organisms could be understood by suppressing the number of pathogenic micro flora and stimulating the host organism's immunity by increasing or decreasing metabolic 
activities. Nevertheless, it should be borne in mind that the probiotics comprise of a significant proportion of biologically active substances that are involved in indirect synthesis of Vitamin B complex, due to which probiotics are essentially bacterial-vitamin preparations that are beneficial to hosts. Alterations in the hematological values using probiotics mainly reflect the physiological and biochemical processes in general, because these parameters are components of a dynamically circulating system. Furthermore, attention should be given to the metabolic processes, the key of which is protein nutrition, because it greatly limits the productivity of animals and birds. All the major attributes of life are associated with the activity of proteins: irritability, contractility, ability to grow, develop, multiply, actively regulate their composition and functions, adaptability to the environment, digestion and excretion of end products of metabolism. ${ }^{13}$ Overall, based on our hematological findings, it can be concluded that the introduction of probiotic "Normosil" tends to stimulate hematopoiesis, in context to hemoglobinopathies and leucopoiesis. The results obtained in this study are in correlation with the previous findings on the dynamics of the increase in live weight of experimental birds. ${ }^{14}$

\section{Biochemical parameter analysis}

The assessment of the biochemical parameters in the serum of broiler chickens of the studied groups at 42-day old are shown in Table 4. The inclusion of probiotic feed additive "Normosil" in the diet of broiler chickens at a concentration of $1 \times 10^{6} \mathrm{CFU} / \mathrm{mL}$ enhanced the metabolism of carbohydrates in the body, which was depicted by the increase in the concentration of blood glucose by $12.3 \%$ and $17.4 \%$ during daily and periodic intake, respectively in comparison to control group. Similar results were obtained in the broilers supplemented with "Normosil" at a concentration of $1 \times 10^{7} \mathrm{CFU} / \mathrm{mL}$ (21.3\% and $6.0 \%$ in the daily and periodic intake groups) in comparison to the control group.

The trend of activation of protein metabolism was most pronounced in the broiler chickens of the experimental groups III and IV, as indicated by an increase in the total protein content in the serum by $0.5 \%$ and $5.7 \%$, respectively. In the experimental group II, the total protein content was $2.5 \%$ higher than that of the control group, whereas it was lower in the experimental group I than in control by $25.8 \%$. AST is an enzyme involved in protein metabolism. It performs a number of important functions, one of which is the participation in the construction of cell membranes and the synthesis of amino acids. Highest concentration of AST is found in the heart, liver, kidneys, muscles and nervous tissue. This is because of the fact that the metabolic processes in these tissues are more active and the cells need to be constantly functioning to maintain their structure. As soon as the cells of these organs begin to break down, the enzyme is actively released into the blood, so its level increases. If the cells remain intact and function normally, then the level of AST remains at a stable level. In the present study, we found that the bacterial composition of the probiotic "Normosil" does not lead to destructive actions on the heart and liver of broiler chickens in the

\begin{tabular}{|c|c|c|c|c|c|}
\hline \multirow{2}{*}{ Indicator } & \multicolumn{5}{|c|}{ Group } \\
\hline & Control & experimental I & experimental II & experimental III & experimental IV \\
\hline Glucose, $\mathrm{mmol} / \mathrm{L}$ & $11.76 \pm 1.12$ & $9.7 \pm 1.1$ & $11.1 \pm 0.34$ & $13.2 \pm 1.24$ & $13.8 \pm 1.18$ \\
\hline Totalprotein, g/L & $31.57 \pm 0.99$ & $25.1 \pm 3.15$ & $32.36 \pm 1.76$ & $31.72 \pm 1.26$ & $33.36 \pm 1.44$ \\
\hline AST, u/L & $512 \pm 82.2$ & $486 \pm 105.0$ & $514 \pm 93.6$ & $417 \pm 91.7$ & $507 \pm 88.4$ \\
\hline $\mathrm{ALT}, \mathrm{u} / \mathrm{L}$ & $17.15 \pm 0.57$ & $16.4 \pm 1.39$ & $19.0 \pm 1.81$ & $17.08 \pm 0.52$ & $17.66 \pm 1.22$ \\
\hline Alkaline phosphatase, $\mathrm{u} / \mathrm{L}$ & $2913.5 \pm 243.0$ & $2349.3 \pm 527.9$ & $3458.3 \pm 329.7$ & $2245.8 \pm 224.0^{*}$ & $2457.6 \pm 387.4$ \\
\hline Albumins & $48.6 \pm 3.12$ & $56.2 \pm 4.18$ & $49.4 \pm 5.22$ & $50.4 \pm 4.84$ & $55.6 \pm 4.76$ \\
\hline $\begin{array}{c}\text { Globulins: } \\
\begin{array}{c}\alpha- \\
\beta- \\
\gamma^{-}\end{array}\end{array}$ & $\begin{array}{c}15.2 \pm 1.24 \\
4.4 \pm 0.46 \\
31.8 \pm 2.86\end{array}$ & $\begin{array}{c}18.6 \pm 1.84 \\
1.8 \pm 0.33^{\star \star *} \\
23.4 \pm 1.75^{*}\end{array}$ & $\begin{array}{l}20.6 \pm 2.15^{*} \\
2.2 \pm 0.64^{* *} \\
27.8 \pm 2.29\end{array}$ & $\begin{array}{c}16.5 \pm 2.34 \\
3.4 \pm 0.71 \\
29.7 \pm 2.43\end{array}$ & $\begin{array}{c}5.8 \pm 0.46^{\star * *} \\
4.1 \pm 0.66 \\
34.5 \pm 4.17\end{array}$ \\
\hline Sodium, mmol/L & $169.2 \pm 8.8$ & $168 \pm 7.28$ & $166 \pm 5.13$ & $172.7 \pm 9.8$ & $177.6 \pm 10.3$ \\
\hline Potassium, $\mathrm{mmol} / \mathrm{L}$ & $8.08 \pm 0.82$ & $8.35 \pm 1.09$ & $10.95 \pm 3.55$ & $9.45 \pm 1.52$ & $10.77 \pm 2.42$ \\
\hline Calcium, $\mathrm{mmol} / \mathrm{L}$ & $0.52 \pm 0.03$ & $0.47 \pm 0.08$ & $0.6 \pm 0.04$ & $0.56 \pm 0.02$ & $0.63 \pm 0.04^{*}$ \\
\hline Inorganicphosphorus, $\mathrm{mmol} / \mathrm{L}$ & $0.451 \pm 0.04$ & $0.355 \pm 0.05$ & $0.294 \pm 0.02^{* *}$ & $0.581 \pm 0.04^{*}$ & $0.358 \pm 0.02$ \\
\hline
\end{tabular}

Note: $*-p<0,05 ; * *-p<0,01 ; * * *-p<0,001$ 
course of its vital activity, which was confirmed by the obtained values of AST in the broiler chickens treated with "Normosil" at a concentration of $1 \times 10^{6} \mathrm{CFU} / \mathrm{mL}$ and $1 \times 10^{7} \mathrm{CFU} / \mathrm{mL}$ that varied between $417-507 \mathrm{u} / \mathrm{L}$ and $486-514 \mathrm{u} / \mathrm{L}$, against $512 \pm 82.2 \mathrm{u} / \mathrm{L}$ in control. It is well known that excessive concentration of ALT in the serum indicates the development of the organ dysfunction and disease progression; liver pathology being the major reason for its increase. Analysis of ALT levels showed that there was a subtle increase in ALT level in the experimental group IV and II by 3.0\% and $10.8 \%$, respectively in comparison to control; however, this increase was in significant as the values still remained within the physiological limits. Analysis of the content of both enzymes in the serum suggested that "Normosil" had low toxicity in broiler chickens during the growing period.

Alkaline phosphatase is an enzyme that is involved in the hydrolysis reaction and is involved in the dephosphorylating of proteins and nucleotides. It is found in many tissues, particularly in the intestinal mucosa. Its levelis determined by the suspected pathology of the liver and kidney. A significant increase in alkaline phosphatase activity is observed during intestinal and bacterial infections. ${ }^{15}$ In this study, serum alkaline phosphatase in the broiler chickens of the experimental group III, I and IV was lower than in control by $29.8 \%$ ( $p<0.05$ ), $24.1 \%$ and $18.6 \%$, respectively. Exceptionally, the alkaline phosphatase content in the experimental group II exceeded the value of the control group by $18.7 \%$, although it was not significant. The obtained results further supported the low metabolic toxicity of the probiotic feed additive "Normosil" upon introduction into broiler chickens.

An important role is played by the plasma lipids and proteins in the implementation of the nutritional function of the blood. The main plasma proteins are albumin, globulin and fibrinogen. Albumin testing is more important than the analysis of total protein. With a wide variety of pathological processes, such as chronic infectious processes, injuries of the skeletal system being manifested in the body, a decrease in the concentration of albumin is, as a rule, universal. This may be due to the transition of albumin into tissue because of an increase in the permeability of vascular walls, decrease in the intensity of albumin synthesis in the renal tissue, acceleration of their breakdown and transformation into other proteins, in particular globulins, the content of which increases accordingly. The results of the protein spectrum of the blood serum in 42-day-old broiler chickens upon administration of probiotic feed additive "Normosil" are shown in Table 4.
We found that supplementation of "Normosil" caused an increase in the serum albumin by $1.7 \%$ in the experimental group II to $15.7 \%$ in the experimental group I compared to the control group. Analysis of globulin fractions showed that the content of serum $\gamma$-globulins in the control group was $31.8 \pm 2.86 \%$, which was higher than that of the experimental group I, II and III by $35.9 \%(p<0.05), 14.4 \%$ and $7.1 \%$, respectively. In turn, the content of serum $\gamma$-globulins in the experimental IV group was $34.5 \%$, which was $8.5 \%$ more than that of the control group. However, such high values of serum globulins cannot be fully reliable as other factors such as chronic inflammatory processes in the body of the bird could be occurring simultaneously that might attribute to such increased levels. In context to the albumin-globulin coefficient, it should be emphasized that a significant decrease in the coefficient is characteristic of liver diseases, accompanied by a decrease in the synthesis of albumin, as well as in the excretion of albumin in the urine due to renal malfunction ( $\mathrm{Hu}$ et al. 2018). In this study, the value of the albumin-globulin coefficient in the experimental groups II and III was close to 1 and was 1.3 in the experimental groups I and IV in comparison to the control group, which was observed at 0.9. Based on our results, we assume that the low values of the albumin-globulin coefficient renders low functional load to the liver, which could be caused by a decrease in the activity of albumin synthesis processes, an increase in the $\gamma$-globulin content and, to a lesser extent, $\beta$-globulin. Therefore, it can be stated that the probiotic feed "Normosil" acts to a certain extent as a factor in reducing the load of the liver function, i.e. conditionally possesses hepato-protective qualities.

The normal course of vital activities provides not only sufficient amount of fats, proteins and carbohydrates in the body, but also the supply of minerals in abundance. The most important element for the body of a bird is calcium. Calcium is necessary for the formation of bone tissue. Calcium is formed in the form of carbonate and phosphate salts in the bones. It is necessary for the normal functioning of the heart, nerves and muscles. It provides protection to the body and regulates the reproductive functions of a bird. Phosphorus is another such element and is one of the major structural elements of the body. All types of metabolic processes occurring in the body are directly related to the conversion of phosphoric acid. Phosphorous is present in the form of organic and inorganic compounds in the blood of birds. It is an active ingredient of the buffer systems and also participates in metabolic reactions. It assists in the intestinal absorption and glycolysis. For the 
absorption of phosphorus, the presence of $\mathrm{Ca}^{2+}$ ions in the chymus is necessary. The results of the level of minerals in the serum of broiler chickens at 42 days of age are shown in comprehensive Table 4 . The activity of mineral metabolism was altered upon administration of "Normosil" in the broiler chickens. Daily and periodic administration of "Normosil" at the concentration of $1 \times 10^{6} \mathrm{CFU} / \mathrm{mL}$ increased the serum sodium content in the broilers of the experimental groups III and IV by $2.1 \%$ and $5.0 \%$; potassium by $17.0 \%$ and $33.3 \%$; calcium by $7.7 \%$ and $21.2 \% \quad(p<0.05)$, respectively. Similarly, daily and periodic administration of $1 \times 10^{7}$ $\mathrm{CFU} / \mathrm{mL}$ Normosil increased the serum potassium content in the broilers of the experimental groups I and II by $3.4 \%$ and $35.6 \%$, respectively; calcium in the experimental group II by $15.4 \%$. However, the serum inorganic phosphorus content was decreased in the experimental groups I, II and IV by $21.3 \%$ and $34.8 \%$, $(p<0.05)$ and $20.6 \%$ respectively, in comparison to control. On the contrary, serum inorganic phosphorus content was higher in the experimental group III than that of the other experimental groups and the control group by $28.8 \%$.Overall, our findings suggested that the administration of probiotic feed additive "Normosil" caused a tendency to enhance the mineral metabolism by the exchange of sodium, potassium and calcium, with a tendency of decreased phosphorus metabolism. In order to discuss the issue of inorganic phosphorus exchange, it might be noted that this compound is present in the serum as anions. Determination of the quantitative value of this element is necessary to assess the state of the calcium-phosphorus balance. The role of inorganic phosphorus is in the regulation of acid-base balance; in addition, phosphates are involved in the metabolism of essential nutrients and the formation of other compounds necessary for the metabolic processes. One of the possible causes of low phosphate content might be attributed to the insufficient intake of vitamin $\mathrm{D}$, or due to issues in the absorption of phosphates in the digestive tract of broiler chickens.

\section{Nutrient digestibility and femur mass analysis}

"Normosil" probiotic micro-organisms secrete enzymes that have modulate the digestibility and nutrient utilization of food. ${ }^{9}$ The results of the nutrient digestibility factors are shown in Table 5. The results showed that the digestibility of organic matter increased by $4.8 \%, 3.7 \%, 6.5 \%$ and $4.4 \%$ in the experimental groups I, II, III and IV, respectively, compared to control group. This trend was also similar to the digestibility of crude protein, which showed that the digestibility coefficient was higher by $2.4 \%$ and $6.2 \%$ in the experimental groups III and IV, respectively, in comparison to control. The coefficient of digestibility of crude fat was also increased by $1.5 \%$ and $5.4 \%$ in the experimental groups III and IV, respectively, in comparison to control. Furthermore, the coefficient of digestibility of nitrogen-free extractive substances was increased in the broilers of the experimental group IV by $12.2 \%$ in comparison to the control group. The digestibility of crude fiber in the experimental group IV was $33.7 \%$, which was $8.7 \%$ higher than that of control. However, it was decreased in the experimental groups II and I by $0.6 \%$ and $3.9 \%$, respectively, in comparison to control. Therefore, it can be suggested that the introduction of "Normosil" probiotic bacteria stimulates efficient digestion of dietary nutrients in the intestines of poultry. An important feature of meat quality is the meat productivity of the experimental poultry and is one of the determining factors characterizing both the size of the slaughter yield and the mass output of the pectoral and femoral muscles. The results of the control slaughter of broiler chickens are shown in supplementary Table S1. Consistent supplementation of "Normosil" probiotic exhibited a greater yield of poultry carcass. The slaughter yield in the experimental groups IV and II $(71.7 \% .73 .5 \%)$ was higher than that of control $(71.4 \%)$. Furthermore, broilers of the experimental group II had more weight of breast meat $(25.5 \%)$ in comparison to control $(24 \%)$. The weight of leg meat

\begin{tabular}{|c|c|c|c|c|c|}
\hline \multirow{2}{*}{ Indicator } & \multicolumn{5}{|c|}{ Group } \\
\hline & Control & Experimental I & Experimental II & Experimental III & Experimental IV \\
\hline Organic matter & $71.2 \pm 1.16$ & $74.6 \pm 1.24$ & $73.8 \pm 2.22$ & $75.86 \pm 2.38$ & $74.3 \pm 1.89$ \\
\hline Crude protein & $82.7 \pm 2.64$ & $85.7 \pm 1.90$ & $86.2 \pm 1.77$ & $84.7 \pm 2.11$ & $87.8 \pm 3.16$ \\
\hline Crude fat & $79.4 \pm 2.39$ & $82.4 \pm 1.77$ & $82.7 \pm 1.81$ & $80.6 \pm 2.43$ & $83.7 \pm 2.66$ \\
\hline Crude fiber & $31.0 \pm 1.65$ & $29.8 \pm 2.60$ & $30.8 \pm 1.05$ & $30.4 \pm 1.18$ & $33.7 \pm 1.61$ \\
\hline Nitrogen-free extractive substances & $72.4 \pm 3.85$ & $75.6 \pm 2.94$ & $74.1 \pm 2.68$ & $78.3 \pm 2.17$ & $81.2 \pm 3.16$ \\
\hline
\end{tabular}




\begin{tabular}{|c|c|c|c|c|c|}
\hline \multicolumn{2}{|c|}{ Table S1: The results of the control slaughter of broiler chickens (M \pm m). } \\
\hline \multirow{2}{*}{ Indicator } & \multicolumn{5}{|c|}{ Groups } \\
\cline { 2 - 6 } & Control & Experimental I & Experimental II & Experimental III & Experimental IV \\
\hline Pre-slaughter weight, g & $2546 \pm 122.6$ & $2793 \pm 116.6$ & $2876 \pm 94.3$ & $2853 \pm 103.6$ & $2910 \pm 114.7$ \\
\hline Weight eviscerated bird. g & $1818.1 \pm 86.6$ & $2027.7 \pm 83.4$ & $2113.9 \pm 66.3$ & $2071.3 \pm 74.8$ & $2086.5 \pm 79.3$ \\
\hline Slaughter yield. \% & 71.4 & 72.6 & 73.5 & 72.6 & 71.7 \\
\hline Weight of breast meat. g & $436.8 \pm 23.7$ & $433.4 \pm 31.5$ & $538.6 \pm 44.5$ & $493.8 \pm 37.3$ & $482.6 \pm 41.7$ \\
\hline In \% ofeviscerated bird & 24.0 & 21.4 & 25.5 & 23.8 & 23.1 \\
\hline Weight of leg meat. r & $179.4 \pm 14.9$ & $181.5 \pm 23.7$ & $212.6 \pm 31.7$ & $208.7 \pm 22.8$ & $198.4 \pm 17.6$ \\
\hline In \% of eviscerated bird & 9.8 & 8.9 & 10.0 & 10.1 & 9.5 \\
\hline
\end{tabular}

\begin{tabular}{|c|c|c|c|c|c|}
\hline \multirow{2}{*}{ Indicator } & \multicolumn{5}{|c|}{ Group } \\
\hline & Control & I-group & II & III & IV \\
\hline Moisture & $69.4 \pm 4.42$ & $72.2 \pm 5.18$ & $71.4 \pm 4.16$ & $66.4 \pm 3.21$ & $68.2 \pm 5.18$ \\
\hline Protein & $16.6 \pm 0.68$ & $18.4 \pm 1.01$ & $17.8 \pm 0.88$ & $17.6 \pm 0.74$ & $19.2 \pm 1.11$ \\
\hline Fat & $12.4 \pm 0.89$ & $8.2 \pm 0.87$ & $9.4 \pm 1.06$ & $14.8 \pm 0.98$ & $11.4 \pm 0.84$ \\
\hline Collagen & $1.6 \pm 0.04$ & $1.2 \pm 0.07$ & $1.4 \pm 0.06$ & $1.2 \pm 0.05$ & $1.2 \pm 0.56$ \\
\hline
\end{tabular}

was the highest in the broilers of the experimental groups II $(10.0 \%)$ and III $(10.1 \%)$. which were higher than that of the control group $(9.8 \%)$. Therefore, the results of meat quality analyses of the experimental broiler chickens suggested that the use of "Normosil" contributes to an increase in the yield of gutted carcass in the broilers. The chemical composition of the femoral muscles of the studied poultry is shown in supplementary Table S2. Analysis of the chemical composition of the femoral muscles of broiler chickens showed that "Normosil" probiotic had a definite influence on the composition. The moisture content of the broilers of the experimental groups I and II increased by $4.0 \%$ and $2.9 \%$ respectively, in comparison to the control group $(69 \%)$. In case of the experimental groups III and IV. The moisture content was decreased by $4.3 \%$ and $1.7 \%$. Respectively. In comparison to control. The biological benefits of the femoral muscles of all the experimental groups were more, which could be further attributed to the high protein content in the experimental groups III and IV by $6 \%$ and $15.7 \%$ in comparison to control. The fat content in the femoral muscles of the experimental groups I. II. and IV was $33.9 \%$. $24.2 \%$. and $8.1 \%$ lower, respectively, in comparison to control. Fat content of the femoral muscles was high was in the broiler chickens of the experimental group III, as it exceeded the control group by $14.9 \%$. The connective tissue content in the femoral muscles of the broilers of all the experimental groups was decreased by $12.5-25.0 \%$ in comparison to control. Therefore, cultivation of broiler chickens using the probiotic feed additive "Normosil" contributes to an increase in the biological benefits of the muscle tissue by increasing the protein content and reducing fat and connective tissue contents. Which further aid in improving the meat quality.

\section{CONCLUSION}

Thus, the inclusion of the probiotic feed additive "Normosil" at a concentration of $1 \times 10^{6} \mathrm{CFU} / \mathrm{ml}$ in the diet of broiler chickens showed a positive effect onthe average daily weight gain and improved the hematological characteristics and biochemical parameters of the broilers' blood. Nutrient digestibility analysis indicated that the probiotic feed additive "Normosil" stimulated efficient digestion of dietary nutrients in the intestines of poultry. Poultry after slaughtering revealed that broiler chickens supplemented with "Normosil" had a greater slaughter yield, higher output of the breast and leg meat. The chemical composition of the femoral muscles of broiler chickens treated with "Normosil" was characterized by a higher protein content, lower fatness and connective tissue of the carcass. This method of feeding of broiler chickens will assist to improve the nutritional quality of meat and enhance poultry weight gain.

\section{CONFLICT OF INTEREST}

The authors declare no conflict of interest. 


\section{Author's contributions}

A $\mathrm{K}, \mathrm{FK}, \mathrm{VK}$, designed the project, conducted experimental work. HT, MR, AA, AB, ZY, MA drafted the manuscript, revised critically the manuscript. All authors agrees and approve the current form of manuscript for publishing.

\section{ABBREVIATIONS}

CFU: Colony Forming Units; L. brevis: Lactobacillus brevis; Lactobacillus plantarum: L. plantarum: L. acidophilus; E. faecium: Enterococcus faecium; Hb: Hemoglobin; AST: Aspartate amino transferase; ALT: Alanine amino transferase.

\section{REFERENCES}

1. Ashayerizadeh O, Dastar B, Samadi F, Khomeiri M, Yamchi A, Zerehdaran S, Effects of Lactobacillus-Based Probiotic On Performance, Gut Microflora, Hematology and Intestinal Morphology in Young Broiler Chickens Challenged with Salmonella typhimurium. Poultry Science Journal. 2016;4(2):157-65.

2. LPZ. The use of Antibiotics in the Agricultural Production of the United States and European Union Countries. https://Www.Portal-Slovo.Ru/ Impressionism/36424.Php 2018, 16.11.2018.

3. (A) Khan S. Probiotic Microorganisms-Identification, Metabolic and Physiological Impact on Poultry. World's Poultry Science Journal. 2013;69(3):601-12. (B) Khachatourians GG. Agricultural use of Antibiotics and The Evolution and Transfer of Antibiotic-Resistant Bacteria. Cmaj. 1998;159(9):1129-36.

4. Khaziakhmetov F, Khabirov A, Avzalov RK, Tsapalova G, Tagirov K, Giniyatullin S, et al. Effects of Paenibacillus-Based Probiotic (Bacispecin) on Growth Performance, Gut Microflora And Hematology Indices In Goslings. Journal of Engineering and Applied Sciences. 2018;13(S8):6541-5.

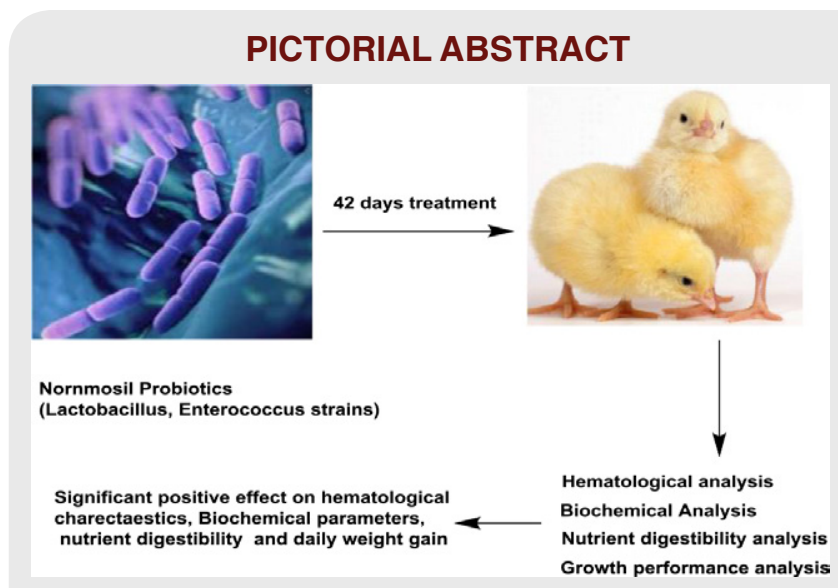

5. Tsapalov GR. The Effectiveness of Probiotics Vitafort and Laktobifadol in Growing of Goslings. News of the Orenburg State Agrarian University. 2016;85-8.

6. (A) Sharipova A, Khaziev D, Kanareikina S, Kanareikin V, Rebezov M, Okuskhanova E, et al. The Effects of a Probiotic Dietary Supplementation on the Livability and Weight Gain of Broilers. Annual Research and Review In Biology 2017;1-5. (B) Sharipova A, Khaziev D, Kanareikina S, Kanareikin V, Rebezov M, Kazanina M, et al. The Effects of a Probiotic Dietary Supplementation on the Amino Acid and Mineral Composition of Broilers Meat. Annual Research and Review in Biology. 2017;1-7. (C) Zarei A, Lavvaf A, Motamedi MM. Effects of Probiotic and Whey Powder Supplementation on Growth Performance, Microflora Population and lleum Morphology in Broilers. Journal of Applied Animal Research. 2018;46(1):840-4.

7. Patterson J, Burkholder, K., Application of Prebiotics and Probiotics in Poultry Production. Poultry Science 2003, 82 (4), 627-631.

8. Ilyasov AS, Khaziakhmetov FS. Using of Probiotic "Normosil" in Feeding of Agricultural Birds. Proceeding of the International Scientific-Practical Conference on "Patterns of Development of Modern Science, Technics and Technology. Belgorod, APNI. 2018;63-6.

9. Khaziakhmetov FS. Rational Feeding of Animals. Saint Petersburg: Lan. 2011. ISBN 978-5-8114-1093-4

10. Coles EH. Veterinary Clinical Pathology $4^{\text {th }}$ Edition. WB. Saunders Co. Philadelphia. 1986. ISBN-13:978-0721618289.

11. Kabir SL, Rahman MM, Rahman M, Rahman M, Ahmed S. The Dynamics of Probiotics on Growth Performance and Immune Response in Broilers. Int J Poult Sci. 2004;3(5):361-4.

12. (A) Nikolenko SS, Ivanov AI. The use of Probiotic "Normosil" and its Effect on the Biochemical Parameters in Pasteurellosis of Cattle. Agricultural Science and Industry at the Turn of the Century. 2015;10:152-5. (B) Shaimuhametov MA, Ivanov A. Comparative Therapeutic Measures for Colibacillosis of Young Cattle. Bulletin of the Orenburg State Agrarian University. 2018;6:140-2.

13. Sethiya NK. Review on Natural Growth Promoters Available for Improving Gut Health of Poultry: An Alternative to Antibiotic Growth Promoters. Asian Journal of Poultry Science. 2016;10(1):1-29.

14. Khabirov AF. Efficiency of Inclusion of Probiotic Fodder Additive "Normosil" in a Chicken-Broiler Compound. Effective Cattle Breeding. 2017;9(139):36-7.

15. Sadeghi G, Pourreza J. Serum Proteins and Some Biochemical Parameters in Broiler Chickens Fed with Raw and Treated Bitter Vetch (Vicia ervilia) Seeds. Pakistan Journal and Biological Science. 2007;10(6):977-81.
The current study was aimed to evaluate the effect of probiotic "Normosil" containing a mixture of living cultures of Lactobacillus and Enterococcus strains on the growth performance, hematological and biochemical parameters of Arbor Acres broilers from a day-old to 42-day. Results showed that Normosil probiotic feed additive "Normosil" at a concentration of $1 \times 10^{6} \mathrm{CFU} / \mathrm{ml}$ in the diet of broiler chickens showed a positive effect on the average daily weight gain and improved the hematological characteristics and biochemical parameters of the broilers' blood. Nutrient digestibility analysis indicated that the probiotic feed additive "Normosil" stimulated efficient digestion of dietary nutrients in the intestines of poultry. Poultry after slaughtering revealed that broiler chickens supplemented with "Normosil" had a greater slaughter yield, higher output of the breast and leg meat. The chemical composition of the femoral muscles of broiler chickens treated with "Normosil" was characterized by a higher protein content, lower fatness and connective tissue of the carcass. This method of feeding of broiler chickens will assist to improve the nutritional quality of meat and enhance poultry weight gain. 


\begin{abstract}
About Authors
Airat Khabirov, Ph.D, Associate Professor, Department of Animal Feeding and Physiology of Bashkir State Agrarian University, Ufa, Russia. Scientific interests: physiological substantiation of probiotic feed additives application in growing of farm animals and poultry.

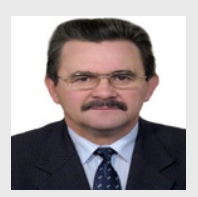

Fail Khaziakhmetov, Doctor of Agricultural Sciences, Professor of the Department of Animal Feeding and Physiology, Honours degree in Education of the Republic of Bashkortostan. Fail Khaziakhmetov's works are aimed at formation of a full-value fodder for livestock breeding with high protein content by using in animal diets forages from high-protein forage crops (rapeseed, soybean, alfalfa, oriental goat-tail). Scientific interests: feed and feed additives, pre - and probiotics, rational feeding of animals and poultry.

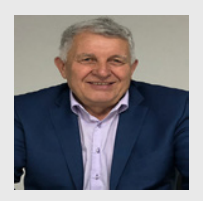

Vyacheslav Kuznetsov, Ph.D, Director of Scientific-innovative enterprise "Bash-Incom". Scientific interests: development and production of microbiological preparations, humic preparations, feed additives, bioactivated fertilizers, probiotics and prebiotics.

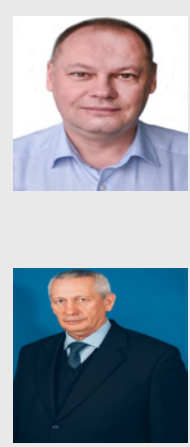

Maksim Rebezov, Professor, Doctor of Agricultural Sciences, Ph.D (Candidate of Veterinary Sciences). He works in the Center of Biophotonics of A. M. Prokhorov General Physics Institute, Russian Academy of Science, Moscow, Russian Federation and Department of Biotechnology and Food Products of Ural State Agrarian University, Yekaterinburg, Russian Federation Scientific interests: biological and biotechnological aspects of food production at different stages of technological processes, conformity and safety assessment of products.

Hamit Tagirov, Doctor of Agricultural Sciences, Professor, Head of the Department of Meat, Dairy Products and Chemistry Technology, Bashkir State Agrarian University, Ufa, Russia. Scientific interests: biological and ecological aspects of intensification of production of high-quality livestock products.

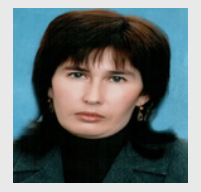

Aleksandra Andreyeva, Ph.D, Associate Professor, Department of Animal Feeding and Physiology of Bashkir State Agrarian University, Ufa, Russia. Scientific interests: the use of natural sources of mineral and biologically active substances in feeding farm animals and poultry.

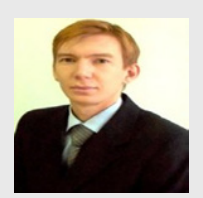

Almaz Basharov, Ph.D, Department of Animal Feeding and Physiology of Bashkir State Agrarian University, Ufa. Russia. Scientific interests: probiotic feed additives for growing young farm animals and poultry, use of biological and chemical preservatives for silage.

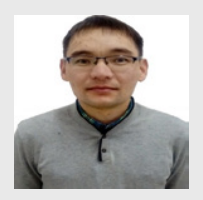

Zhanibek Yessimbekov, Ph.D, Food Engineering Department of Shakarim University of Semey, Semey city, Kazakhstan. Research area - animal science, meat science, food technology.

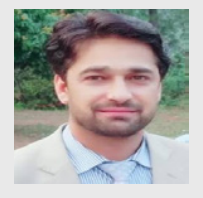

Dr. Muhammad Ayaz is working at Department of Pharmacy University of Malakand. His research interests include natural products, green synthesis of nanoparticles, synthesis of compounds and more importantly their pharmacological evaluations. Currently active projects include Alzheimer's disease, it's behavioral and neurochemical analysis and screening of these compounds against various pathological targets of diseases including diabetes, inflammation and cancer cells. Serving as associate editor at several journals including Frontiers in Pharmacology, BMC complementary and alternative medicine and many more.
\end{abstract}

Cite this article: Khabirov A, Khaziakhmetov F, Kuznetsov V, Tagirov H, Rebezov M, Andreyeva A, et al. Effect of Normosil Probiotic Supplementation on the Growth Performance and Blood Parameters of Broiler Chickens. Indian $\mathrm{J}$ of Pharmaceutical Education and Research. 2020;54(4):1046-55. 